\title{
Agricultura urbana, governança territorial e planejamento urbano em área protegida de Manaus - Brasil
}

\author{
Urban agriculture, territorial governance and urban planning \\ in an environmental protection area of Manaus - Brazil
}

Camila Garcia Fernandes de Souza Margem [I] Neliton Marques Silva [II]

\begin{abstract}
Resumo
Este artigo aborda a convergência da prática da agricultura urbana (AU) com os propósitos das Áreas de Proteção Ambiental (APAs), da política urbana municipal e do abastecimento alimentar. Objetivou-se analisar a viabilidade de implementação da AU em terrenos ociosos inserto na APA Tarumã - Ponta Negra, Manaus-AM, enquanto instrumento de governança territorial e planejamento urbano. Foram aplicadas entrevistas semiestruturadas e técnicas de Sobreclassificação e Ordenamento de Cartões junto à população-alvo. Constatou-se que a utilização de terrenos ociosos para a $\mathrm{AU}$ não é vislumbrada como instrumento de governança territorial. Situação agravada pela atuação do poder municipal que inviabiliza a legitimação de projetos de lei acerca da destinação de terrenos ociosos para tal prática.
\end{abstract}

Palavras-chave: produção alimentar; áreas protegidas; planejamento urbano; uso da terra.

\begin{abstract}
This article addresses the convergence of urban agriculture with the purposes of environmental protection areas (EPA), of the municipal urban policy and of the food supply chain. The objective was to evaluate whether it is possible to implement an urban agriculture project in vacant land inside the Tarumã-Ponta Negra EPA, in the city of Manaus, State of Amazonas, as an instrument for territorial governance and urban planning. Semi-structured interviews were conducted with the target population and the Outranking and Card Sorting techniques were used. The results showed that the utilization of vacant land for urban agriculture is not perceived as a territorial governance instrument. The situation is aggravated by the action of the municipal government, which prevents the legitimation of bills dealing with the use of vacant lots for such practice.
\end{abstract}

Keywords: food production; protected areas; urban planning; land use. 


\section{Introdução}

A cidade de Manaus, no estado do Amazonas, depende da importação de gêneros alimentícios para o abastecimento da população local desde o século XIX. Embora o município, no transcorrer do século XX, tenha estruturado um sistema produtivo com vistas ao próprio abastecimento (Distrito Agropecuário da Suframa - DAS), ainda hoje a produção de alimentos não atende à demanda populacional, perpetuando essa dependência (Bicalho, 2005; Homma, 2015).

Contudo, é imperativo atender a necessidade diuturna de alimentos de cerca de 2.200.000 habitantes do município, dos quais $90 \%$ integram a população urbana. É válido ressaltar que Manaus possui cerca de $20 \%$ de seu território composto por Áreas Protegidas, cujo cerne é a sustentabilidade ambiental, o que corrobora a necessária implementação de práticas que visem à conservação dos ecossistemas locais e que promovam a qualidade socioambiental e o acesso aos bens alimentares (Semmas, 2018).

Nesse contexto, e diante da prerrogativa de que o abastecimento alimentar articula diversos aspectos urbanos e socioambientais, ganha destaque a prática da agricultura urbana, esta centrando-se no uso de terrenos potencialmente produtivos, disseminados no interstício da malha urbana, (re)aproveitando recursos - inclusive humanos - e insumos locais (Morgan e Sonnino, 2010; Videiro Rosa, 2011).

Tal prática tem o potencial de contribuir com a produção de alimentos em bases locais, com repercussões à segurança e à soberania alimentar, e converge com os objetivos das Áreas de Proteção Ambiental - APA e da política urbana municipal, regulamentada pela lei n. 2 de 16 de janeiro de 2014, que dispõe sobre o Plano Diretor e Ambiental de Manaus, este último em consonância com a lei federal n. 10.257 de 2001 - Estatuto da Cidade - e com a Constituição Federal de 1988 (Altieri, 2010; Semmas, 2018).

Isto posto, urge a busca por uma governança entre os diferentes atores que promovem a gestão pública e o disciplinamento do uso do solo, especialmente da zona urbana. Encontrando-se aí o poder público e os diferentes segmentos que desenvolvem suas atividades nessas áreas protegidas, em particular na APA Municipal Tarumã - Ponta Negra, Unidade de Conservação de Uso Sustentável, na qual está inserta a localidade Campos Sales (Figura 1), unidade espacial objeto do estudo.

Assim, o objetivo geral deste estudo consistiu em avaliar a viabilidade de implementação da agricultura urbana em terrenos não utilizados na localidade de Campos Sales, como instrumento de governança territorial e planejamento urbano.

Partindo de uma abordagem hipotético-dedutiva, com finalidade exploratório-descritiva (Marconi e Lakatos, 2003), a pesquisa se referencia na hipótese de que os terrenos ociosos na área em questão podem ser destinados à prática da agricultura urbana, tendo como premissa a existência de instrumentos jurídicos que permitem a utilização compulsória de tais espaços.

Dessa forma os objetivos específicos da pesquisa consistiram em: 1) identificar os terrenos subutilizados e/ou não utilizados na localidade Campos Sales e os mecanismos fiscais para a utilização compulsória deles; 2) identificar a demanda pela utilização compulsória dos terrenos subutilizados e/ou não utilizados para 
Figura 1 - Mapa de situação da localidade Campos Sales em relação à APA Tarumã-Ponta Negra - 2019

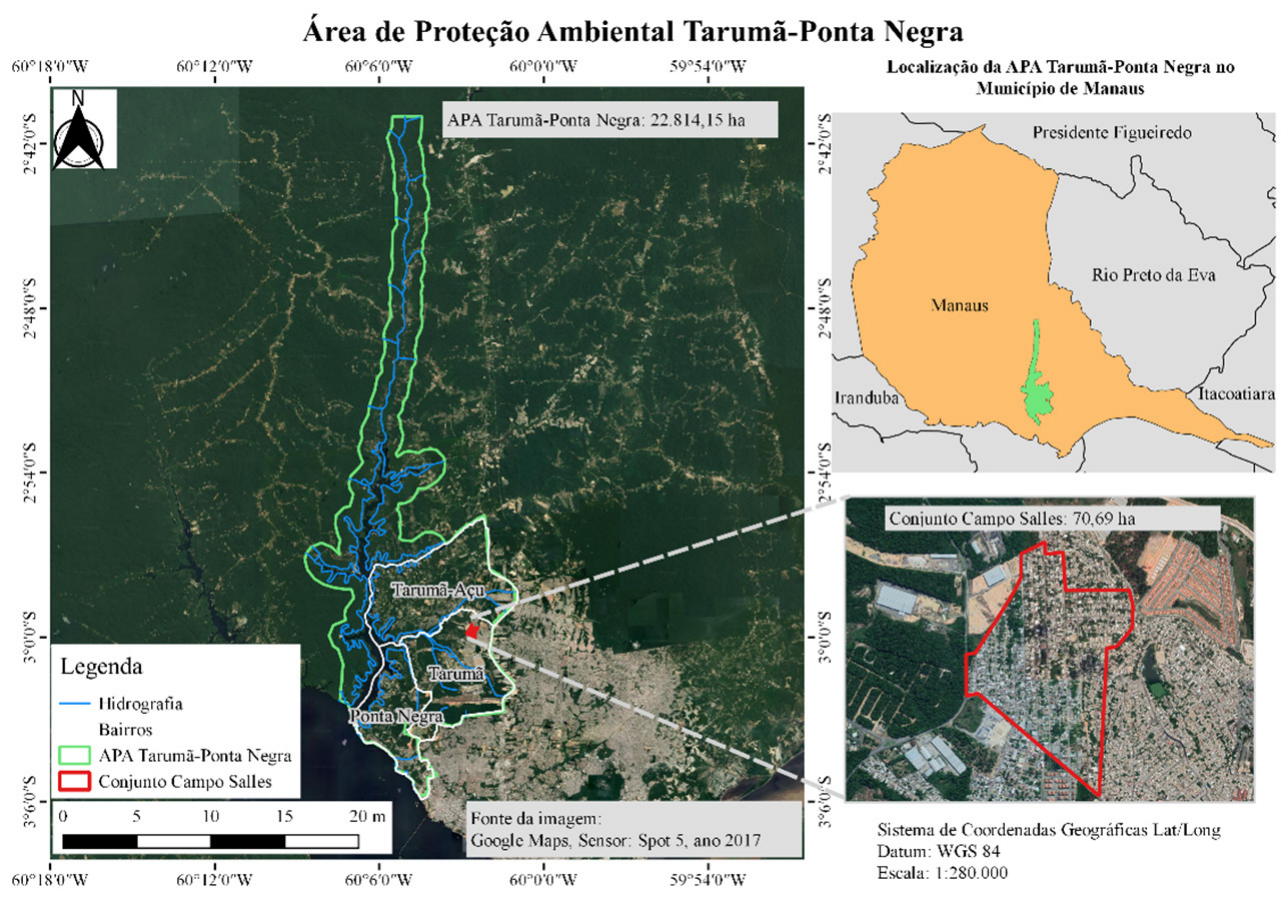

Fonte: Elaborado pela autora.

a prática da agricultura urbana; e 3) mapear a atratividade das variáveis sociais, econômicas e ambientais para a prática da agricultura urbana na unidade espacial do estudo.

0 arcabouço metodológico consistiu na adoção de pesquisa bibliográfica, documental e de campo, além de entrevistas semiestruturadas junto à população local, aplicando-se a Técnica de Análise de Conteúdo. Complementarmente às entrevistas, foram aplicadas técnicas de Sobreclassificação, com posterior agrupamento dos dados mediante a técnica de Diagrama de Caixa (Boxplot) e Ordenamento de Cartões (Card Sorting), com posterior análise mediante construção de um dendrograma. 


\section{Governança territorial, agricultura urbana e conservação ambiental - estabelecendo vínculos}

A governança, enquanto uma abordagem conceitual distinta de governo, disseminou-se a partir dos anos 1990, num cenário mundial de ajuste estrutural do papel dos Estados Nacionais nas políticas públicas. Esse ajuste, relacionado à doutrina econômica neoliberal, impulsionou a desestatização e redundou na descentralização tanto dos processos decisórios como da gestão das políticas públicas. Sem desconsiderar, nesse processo de mudança, o papel dos grupos sociais, descrentes com a atuação governamental até aquele momento vigente, que demandavam maior participação social (Câmara, 2013; Peci, Pierante e Rodrigues, 2008).

No cenário brasileiro, há a institucionalização da discussão acerca da governança com a promulgação da Constituição Federal de 1988, a qual trouxe importantes inovações, tais como a universalização do acesso às políticas, a ampliação dos temas tratados pela Constituição, a reformulação do Federalismo e a democratização das decisões governamentais, conforme apontado por Lima, Abrucio e Silva (2014), trazendo repercussões diretas à análise da governança em bases territoriais e às legislações de caráter socioambiental.

Da reformulação do federalismo emerge a definição da governança territorial, a partir do reconhecimento de que o território é o recorte espacial no qual diversas modalidades de gestão de atividades se desmembram, mobilizando processos de negociação entre atores sociais distintos - empresas, prefeituras, sindicatos, associações, sociedade civil -, manifestando diferentes formas de conflito e de cooperação (Pires et al., 2011; Dallabrida, 2011).

Complementarmente, os municípios, já consagrados na matriz político-institucional brasileira como escala espacial da realização dos processos políticos e administrativos de gestão de funções públicas de interesse comum para o desenvolvimento territorial, bem como para solução de problemas através de políticas públicas locais e do planejamento urbano (Frey, 2007; Kornin e Moura, 2004; Pires et al., 2011), passaram, com a promulgação da Constituição Federal e posteriormente com a regulamentação da lei n. 10.257 de 2001 Estatuto da Cidade, a dispor de um conjunto inovador de diretrizes e instrumentos de intervenção sobre seus territórios, criando possibilidades ao exercício da governança territorial.

Nesse sentido, destacam-se: a instituição do Plano Diretor como instrumento básico da política urbana; a inclusão da participação popular no processo de planejamento; e a determinação de que a propriedade urbana deve cumprir uma função social - Princípio da Função Social da Propriedade Urbana. Este último estabelecendo uma prerrogativa que permite o acesso a áreas ociosas na cidade. A exemplo de imóveis abandonados e terrenos baldios que podem ter seu uso reivindicado em prol de ações que promovam a justiça social, através dos instrumentos de Parcelamento, Edificação e Utilização Compulsórios (PEUC) e do Imposto Predial e Territorial Urbano Progressivo (IPTU progressivo), os quais, mediante regulamentação municipal específica, incidem sobre o solo urbano não edificado, subutilizado ou não utilizado (Rolnik, 2001; Videiro Rosa, 2011). 
Na contextualização da emergência desse conjunto inovador de diretrizes e instrumentos de intervenção territorial, urge destacar, ainda, a articulação que ele possui com as questões ambientais, incluídas no rol de novos direitos tratados no artigo 225 da Constituição Federal.

Considerando-se, portanto, que o Poder Público se manifesta nos três entes federativos e que o município detém a autonomia para promover o ordenamento territorial mediante a definição de padrões de uso e ocupação do solo via Plano Diretor, não há como segregar as ações necessárias para a manutenção do equilíbrio ambiental da política urbana no espaço territorial da municipalidade (Leuzinger e Scardua, 2011; Marchesan, 2011).

Nesse sentido, Marchesan (ibid.) pontua que qualquer norma infraconstitucional que tenha interface ambiental, destacando-se os Planos Diretores detalhados pelo Estatuto da Cidade, deve ser interpretada em jurídica correlação com os princípios do direito ambiental.

$\mathrm{Na}$ realidade urbana da cidade de Manaus, é imperativa essa articulação, já que ela possui cerca de $20 \%$ de seu território composto por Áreas Protegidas, cujo cerne é a sustentabilidade ambiental, o que corrobora a necessária implementação de práticas que visem à conservação dos ecossistemas locais e que promovam a qualidade socioambiental (Semmas, 2018).

No que concerne a uma Área de Proteção Ambiental, destaca-se que essa categoria de unidade de conservação foi proposta como um modelo de proteção para resguardar áreas com certo nível de ocupação, sobretudo em áreas urbanas, permitindo a existência de propriedades privadas sob o domínio territorial dela, mas sujeitas a regimes especiais de administração quanto ao uso do solo e dos recursos naturais (Côrte, 1997; Medeiros, 2006).

Essa situação, conforme Côrte (1997) concorre para superar a concepção de que a conservação do meio ambiente e dos recursos naturais só é possível mediante o distanciamento da espécie humana dessas áreas e, concomitantemente, impõe a busca de práticas de sustentabilidade que promovam a convivência harmônica do ser humano e dos sistemas produtivos com o meio em que vive.

É possível, portanto, relacionar os benefícios tangíveis que as APAs oferecem à sociedade - na forma de bens e serviços, inclusive participando do desenvolvimento social e econômico das populações usuárias (ibid.) - com as premissas da agricultura urbana, em especial no que tange à utilização: dos residentes urbanos como trabalhadores, de terrenos ociosos, de recursos urbanos típicos (como resíduos orgânicos para compostagem), entre outros, configurando uma opção promissora de geração de trabalho, renda e desenvolvimento local, capaz de contribuir com a gestão da área e o uso sustentável de seus recursos ambientais (Espada e Sobrinho, 2015).

Esse cenário não afasta a possibilidade do surgimento de conflitos quanto ao uso dos recursos naturais de uma APA e seus objetivos conservacionistas, ao mesmo tempo que não há harmonia ou equilíbrio entre as relações socioeconômicas e socioambientais. Nesse sentido, é primordial que a gestão dessas áreas busque a mediação desses conflitos e alcance as políticas e os instrumentos de planejamento urbano e gestão territorial (Côrte, 1997; Figueiredo et al., 2017). 
Agricultura urbana nas políticas públicas brasileiras e seu potencial socioeconômico

É possível pontuar que a raiz filosófica das prolíficas conceituações sobre agricultura urbana é única e sinaliza para a necessidade em se superar a dicotomia, estabelecida a partir da Revolução Industrial, que coloca a cidade como lugar do aperfeiçoamento técnico e de atividades não agrícolas e o campo como produtor de um excedente alimentar a ser destinado à anterior (Aubry e Pourais, 2013; Coutinho e Costa, 2011).

A discussão acerca do aspecto urbano na conceituação dessa categoria no cenário brasileiro é de extrema importância, pois, conforme Lemos, Andrade e Medeiros (2015): "há uma lacuna quanto às ações e práticas de agricultura urbana no âmbito legal de uso e ocupação do solo", já que as políticas públicas que fomentam a agricultura urbana enfocam sobretudo a segurança alimentar e nutricional (Mass, Malvestiti e Gontijo, 2020) e a legislação sobre o tema ainda é escassa, com reduzido desenvolvimento legislativo sobre o tema na última década (Lara et. al, 2019).

Nesse sentido, vale destacar que recentes iniciativas de instituição de uma Política Nacional de Agricultura - PL 182/2017 (PL 906/2015 na origem) e PL 353/2017, que, desde 2018, tramitam em conjunto por tratarem da mesma matéria (Larcher, 2017; Senado Federal, 2018) - contempla em seus objetivos a questão da ocupação de espaços urbanos ociosos, articulando-se com o instrumento de Parcelamento, Edificação e Utilização Compulsórios (PEUC), conforme já discutido anteriormente.
Nesse cenário, ganha destaque o papel da política urbana municipal como uma legislação de relevância ocasional para a promoção da agricultura urbana (Videiro Rosa, 2011), enquanto um modelo produtivo capaz de fomentar a produção intraurbana de alimentos, incentivando o uso de terrenos para o plantio, os quais existem em quantidade nas cidades brasileiras (Dambrós e Miorin, 2011; Orsini et al., 2013).

Diante da interface existente entre agricultura urbana e outros temas (como o quadro de desigualdade social e de marginalização econômica, a segurança alimentar e nutricional, e o abastecimento endógeno com reflexos positivos à sustentabilidade das e nas cidades), é imprescindível que os processos de planejamento urbano pensem a agricultura urbana como uma variável que faz parte da dinâmica de uso e ocupação do solo, na mesma magnitude que as questões habitacionais, de segurança e transporte (Coutinho e Costa, 2011).

\section{0 acesso físico e jurídico aos terrenos ociosos na localidade Campos Sales}

A identificação dos terrenos ociosos objetivou, para além do registro de suas coordenadas geográficas, a coleta de dados relativos à matrícula desses terrenos em órgãos da Prefeitura Municipal, em particular do Instituto Municipal de Planejamento Urbano (Implurb) e da Secretaria Municipal de Finanças, Tecnologia da Informação e Controle Interno (Semef), especificamente no que tange à regularidade fiscal de tributos. Diante desse aspecto, buscou-se 
inicialmente, junto a esses órgãos, algum tipo de documento que versasse sobre "cadastro de terrenos ociosos/baldios/não utilizados" ou qualquer outra denominação correlata.

Em função da inexistência de documentos/relatórios e/ou cadastros nesse sentido, para a obtenção dos dados supracitados, seria necessário dispor do número do lote do terreno, o qual poderia ser consultado na base de cadastro daqueles órgãos. Assim, duas importantes dificuldades se apresentaram: a defasagem da base cadastral relativa ao ano de 2010 e o fato de que, por tratar-se de uma área ocupada irregularmente, a numeração dos terrenos, quando existente, não condiz com a dos lotes na base cadastral.

Dessa forma, o registro fotográfico dos terrenos, durante a pesquisa in loco, ganhou maior importância, pois a partir destes será possível, em estudos futuros no curto prazo, realizar a comparação com as imagens da base cadastral dos órgãos já citados, identificar o número do lote e efetivamente ter acesso à situação da regularização fiscal e mesmo fundiária dos terrenos.

Das visitas à área de estudo, e com o auxílio dos 30 moradores entrevistados, foi possível identificar 44 terrenos que evidenciavam abandono, pela presença de espécies vegetais pioneiras ou de muros/cercas/casas depredados no interior do lote. Esses terrenos perfazem uma área potencialmente disponível para a prática de agricultura urbana de $14.316 \mathrm{~m}^{2}$ (Figuras 2, 3 e 4).

\section{Mecanismos fiscais para utilização compulsória de terrenos ociosos. Entraves e incongruências para a gestão de espaços urbanos}

Diante da possibilidade de legislar de forma concorrente e suplementar à política urbana, no âmbito do município, a Câmara de Vereadores de Manaus submeteu, no ano de 2017, dois projetos de lei, relativos à possibilidade de utilização de terrenos ociosos para a prática da agricultura urbana, sendo estes: o PL 265/2017, que visa a instituir no âmbito do município de Manaus o programa "Horta Comunitária" e dá outras providências, e o PL $326 / 2017$, que visa a autorizar a criação do programa de aproveitamento de terrenos baldios do município de Manaus para o cultivo de hortaliças e dá outras providências.

Nenhum dos projetos foi aprovado pela 2a - Comissão de Constituição, Justiça e Redação e pela Procuradoria Legislativa, segundo a alegação de que apresentavam vício de iniciativa, oferecendo impedimentos à sua tramitação (óbice legal, na linguagem jurídica).

O fundamento principal da justificativa daquelas instâncias concentra-se no aspecto de que as matérias tratadas por ambos os PLs preveem o aumento de despesas ao Executivo Municipal e obrigações a órgãos da prefeitura de Manaus, os quais são administrados pelo 
Figura 2 - Mapa dos terrenos ociosos no Campos Sales (2019)

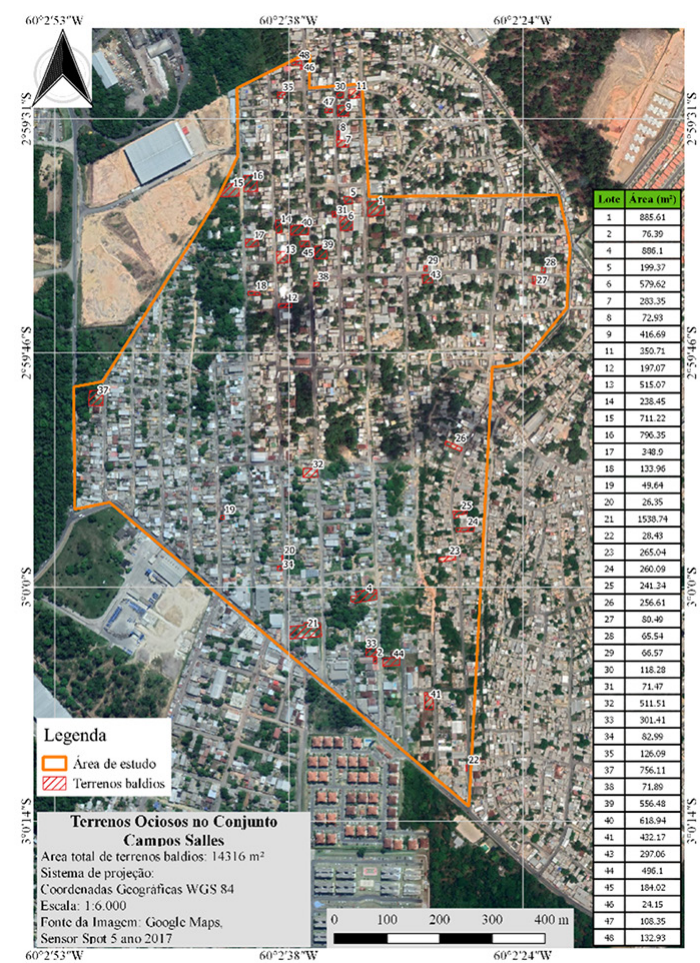

Fonte: elaborado pelos autores.

Obs.: algumas numerações de terreno foram descartadas devido a inconsistências com os critérios de inclusão.

Figura 3 - Terreno 1 (2019)

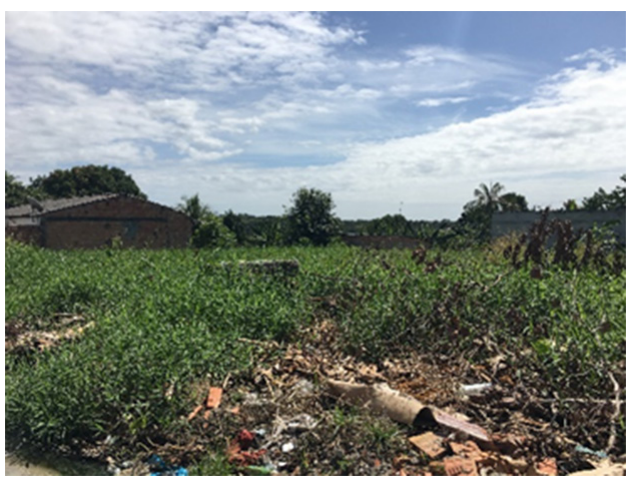

Fonte: acervo dos autores.

Obs.: segundo relatos dos moradores, este terreno teria sido desapropriado pela prefeitura para a construção de uma escola.
Figura 4 - Terreno 6 (2019)

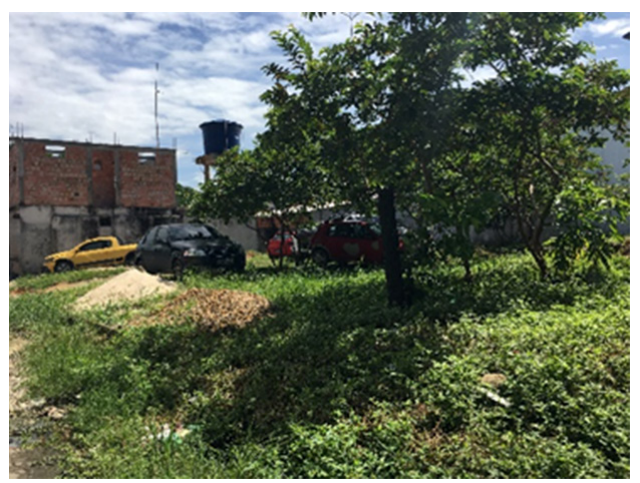

Fonte: acervo dos autores.

Obs.: terreno utilizado por uma oficina e serviço de lava jato, situado de fronte ele, mas sem o conhecimento do proprietário, conforme apontado pelos entrevistados. 
prefeito e, portanto, cabendo a ele, privativamente, a iniciativa de leis que digam respeito a criação, estruturação e definição de atribuições dos órgãos da administração direta, indireta e fundacional do município, conforme o artigo n. 59 da Lei Orgânica do Município de Manaus (Loman).

Acerca do processo legislativo municipal e, no sentido de contribuir com a discussão mais ampla sobre governança, cabe inquirir sobre a fundamentação jurídica, interpretação e repercussão do conteúdo do artigo n. 59 da Lomam, para a atuação parlamentar no município, e os meios de se superar o entrave representado por este artigo.

Embora a redação do conteúdo do artigo n. 59 seja consoante ao Princípio da Divisão dos Poderes, ao Princípio da Simetria e disciplinada pelo artigo n. 61 da Constituição Federal (Maurano, 2007; Nascimento, 2019; Thuler, 2017), há que se discutir sobre a sua interpretação, em particular, em face do Tema 917 de Repercussão Geral do Superior Tribunal Federal, o qual determina que: "não usurpa a competência privativa do chefe do Poder Executivo lei que, embora crie despesa para a administração pública, não trata da sua estrutura ou da atribuição de seus órgãos nem do regime jurídico de servidores públicos" (STF, 2016a e 2016b), conforme explicitado na redação do artigo 61, § 1ํ, II,'a', 'c' e 'e', da Constituição Federal.

Com relação a isto, explica-se que se excetuando as matérias expressamente previstas pelo referido artigo, e seus correspondentes nas leis estaduais e municipais, nenhuma outra pode ser declarada inconstitucional por vício de iniciativa, já que a interpretação dada pela Suprema Corte é restrita às matérias constantes do rol taxativo do artigo aqui em destaque e não ampliativa das matérias que são de iniciativa privativa do chefe do Poder Executivo tanto na esfera municipal quanto na estadual (Fátima da Silva, 2018; Thuler, 2017).

Ainda sobre o Tema 917 do STF, Thuler (2017) pontua que a não aplicação desse entendimento na ampla maioria dos casos é recorrente, o que, na prática, limita a atuação e a produção legislativa dos vereadores, principalmente no que concerne à elaboraçãos de leis com impacto social, político e econômico (Thuler, 2017; Fátima da Silva, 2018; Pires, 2013).

Isto, em paralelo com a discussão sobre governança, implica dizer que não há uma repartição igualitária de poderes entre o executivo e o legislativo municipal, havendo, sim, uma primazia do primeiro a qual denota a ainda presente tradição centralizadora na cultura política, que reproduz um modelo de gestão que vai contra os preceitos do processo de descentralização fundamentais à governança no âmbito de qualquer política pública, conforme salientado por Junqueira (1998) e pelo Instituto Brasileiro de Administração Municipal - Ibam (2009).

Assim sendo, entende-se que o impedimento de progressão dos PLs n. 265/2017 e n. 326/2017 à votação no Plenário da Câmara baseia-se numa interpretação ampliativa do que consta no texto Constitucional. Embora os PLs em questão estivessem dirigidos ao Poder Executivo Municipal e impusessem a execução de ações concretas, não detalhavam ou especificavam em minúcias as condutas a serem realizadas pela Administração Municipal para sua a concretização(Fátima da Silva, 2018).

Desta forma, a inviabilização do PL n. 265/2017 (Programa "Horta Comunitária") e do PL n. 326/2017 (Programa de Aproveitamento de Terrenos Baldios) dificulta a 
emergência de alternativas à solução de problemas socioambientais que derivam da existência de terrenos ociosos distribuídos pelos diversos bairros do município, em particular na localidade Campos Sales. Essas alternativas, atuando em consonância com preceitos legais, têm o potencial de desonerar a atuação do poder executivo em questões relativas aos problemas decorrentes do abandono dessas áreas.

Pode-se considerar como uma possibilidade de superação do entrave interpretativo do conteúdo do artigo 59 da Lomam, a reapresentação de tais PLs numa nova sessão legislativa, conforme ofertado dentro do processo legislativo, e, ante um novo parecer de inadmissibilidade da CCJR, é possível requerer tal decisão, conforme expresso pelo Artigo 38 do Regimento Interno da Câmara Municipal, fundamentando-se para isso no Tema 917 do STF.

\section{Demanda pela utilização compulsória dos terrenos subutilizados e/ou não utilizados no Campos Sales para a prática da agricultura urbana}

Os dados coletados nas entrevistas realizadas com 30 moradores do Campos Sales indicam que, do universo total da amostra, $73 \%$ dos participantes possuem o hábito de cultivar espécies vegetais no espaço domiciliar, uma sinalização positiva na perspectiva de dar visibilidade à prática da agricultura urbana. Tal hábito não necessariamente possui relação com os níveis de escolaridade dos respondentes (Gráfico 1) ou com o nível de renda familiar
(Gráfico 2) e está ligeiramente mais difundido entre as mulheres (Gráfico 3).

Outra variável que contribui com a perspectiva de dar visibilidade à prática da agricultura urbana se relaciona a aspectos motivacionais conforme proposto por Pessôa (2005). Assim, o hábito de cultivar relaciona-se à satisfação da necessidade básica de consumo (alimentação), seguido pela satisfação da necessidade de lazer, que, na perspectiva de Faleiros (1980), engloba descanso, divertimento, recreação e entretenimento (Gráfico 4).

0 aspecto motivacional relativo ao lazer enseja grandes possibilidades de utilização compulsória dos terrenos subutilizados e/ou não utilizados no Campos Sales para a prática da agricultura urbana, já que, conforme a concepção de Dumazedier (2000), permite ao indivíduo, para além da entrega a uma ocupação de livre vontade, o desenvolvimento de sua informação ou formação desinteressada, sua participação social voluntária ou sua livre capacidade criadora.

Sem desviar-se do intuito de investigar a demanda pela utilização compulsória dos terrenos ociosos para a prática da agricultura urbana, mas diante da finalidade exploratório-descritiva da pesquisa, preliminarmente a qualquer menção sobre a agricultura urbana e a utilização dos terrenos para essa prática, foi solicitado aos entrevistados que atribuíssem opiniões acerca da presença dessa tipologia de terreno na área de estudo (Gráfico 5), bem como a sugestão de possíveis usos para esses espaços (Gráfico 6).

A prevalência de opiniões relativas à nocividade (C1-46\%) tangencia o aspecto da criminalidade, voltando-se à ocupação desses terrenos para a prática de atos ilícitos, como consumo e distribuição de drogas, realização 
Gráfico 1 - Presença do hábito de cultivar espécies vegetais por nivel de escolaridade dos respondentes.

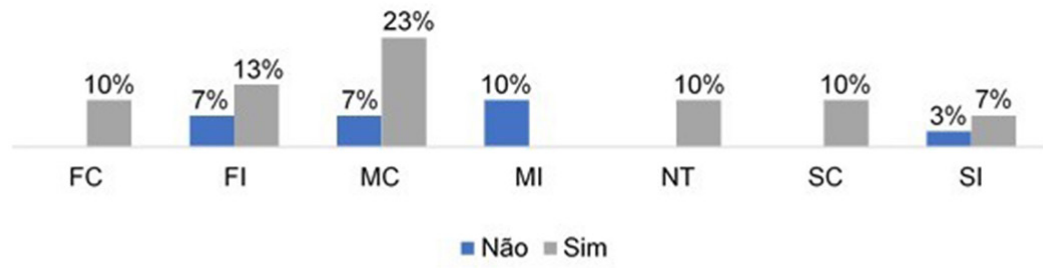

\section{Legenda:}

FC- Fund. Completo / FI- Fund. Incompleto / MI- Médio incompleto / MC- Médio completo

SI-Sup. Incompleto / SC- Sup. Completo / N T- Ensino Técnico completo

Gráfico 2 - Presença do hábito de cultivar por faixa de renda salarial em salários mínimos (valor de referência 2019)

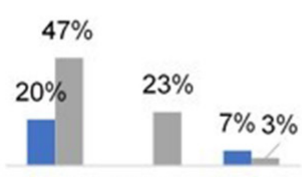

Até 2 Entre 2 Acima

s.m. e 4 s.m. de 4 s.m.
Gráfico 3 - Presença do hábito de cultivar segundo o sexo biológico do respondente
Gráfico 4 - Motivos atribuidos ao hábito de cultivar $82 \%$

$$
\text { घNão }=\operatorname{Sim}
$$
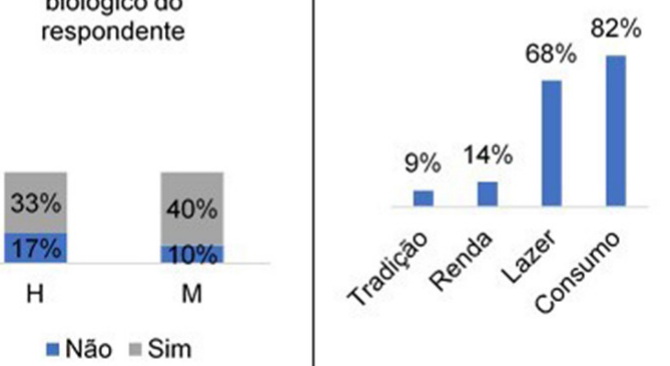

Gráfico 5 - Distribuição das opiniões expressas relativas à presença de terrenos ociosos no Campos Sales

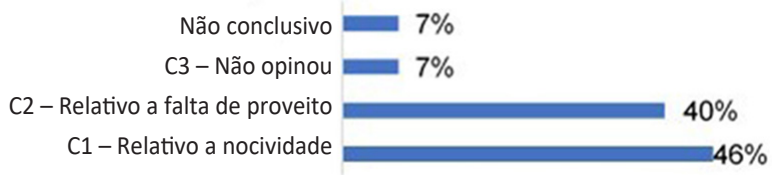

\section{Legenda}

C1 - Relativa a nocividade: particularidade do que prejudica, do que faz uma pessoa ser lesada ou sofrer algum dano.

C2 - Relativa a falta de proveito: consequência de um uso que não gera benefício. 
Gráfico 6 - Distribuição das categorias de uso sugeridas pelos entrevistados

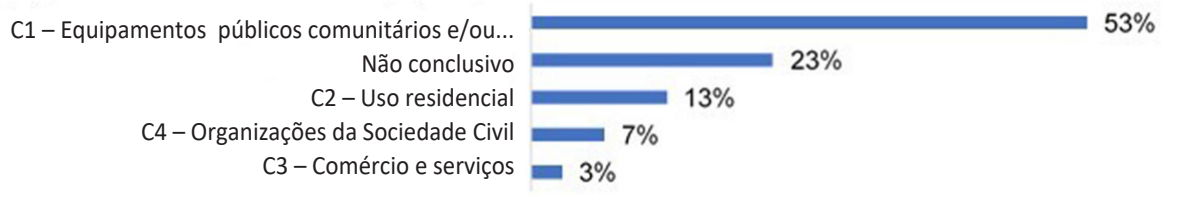

\section{Legenda}

C1 - Equipamentos públicos comunitários (1) e/ou urbanos (2)

(1) Fornecidos por meio do Estado, destinados aos serviços públicos de educação, saúde, cultura, assistência social, esportes, lazer, segurança pública, abastecimento, serviços funerários e congêneres, conforme artigo 2으, inciso II, parágrafo 2o, do decreto n. 7.341 de 2010, em atendimento à realização dos direitos fundamentais sociais, conforme redação dada pelo artigo 6o da CF de 1988;

(2) Consideram-se equipamentos públicos urbanos as instalações e os espaços de infraestrutura urbana destinados aos serviços públicos de abastecimento de água, esgotamento sanitário, coleta de águas pluviais, disposição e tratamento dos resíduos sólidos, transporte público, energia elétrica, rede telefônica, gás canalizado e congêneres

C2 - Uso residencial

Para aplicação das normas de uso e ocupação do solo na área urbana e na Área de Transição, são considerados os seguintes usos: I-residencial: a) unifamiliar - uma ou duas unidades habitacionais autônomas por lote; b) multifamiliar - mais de duas unidades habitacionais autônomas por lote - art. 37, lei n. 1.838, de 2014, Manaus - AM.

C3 - Atividades comerciais e de serviços

Atividades que podem conviver com o uso residencial sem limitações específicas à sua localização, que não oferecem riscos à segurança nem incômodo à vizinhança e não provocam impactos significativos ao ambiente, à estrutura e à infraestrutura urbana e a atividades de pequena e média escala de operação - lei municipal n. 1.838, de 2014, Manaus - AM.

C4 - Organizações da Sociedade Civil

Organizações da sociedade civil - União de pessoas que se organizam para fins não econômicos (lei n. 10.406 de 2002 - Código Civil), que podem ser socioeducativos ou pela busca de melhorias para a comunidade.

de furtos e estupros (Quadro 1), o que alerta para a necessidade de estudos futuros que se aprofundem sobre os impactos e as possibilidades de contemplação dessa outra forma de organização social na discussão sobre governança territorial na área de estudo em questão.

No sentido de uma atribuição de usos aos terrenos ociosos, é prevalente a demanda por equipamentos públicos comunitários e/ou urbanos. A menor prevalência de uso, concernente ao uso comercial e de serviços, tangencia o objeto da investigação acerca da demanda da utilização desses terrenos para a prática da agricultura urbana (Quadro 2), na perspectiva de que essa atividade se articula com o abastecimento intraurbano (Videiro Rosa, 2011).

Embora a demanda pela utilização dos terrenos ociosos para atividades que envolvam algum tipo de cultivo de espécies vegetais seja extremamente reduzida, os entrevistados quando solicitados a opinarem sobre a possibilidade de realização desse tipo de atividade nos terrenos (enfocando concomitantemente outros preceitos da agricultura urbana, 
Quadro 1 - Verbalizações dos entrevistados relativas à nocividade representada pelos terrenos ociosos no Campos Sales

\begin{tabular}{|c|c|}
\hline & Verbalizações \\
\hline \multirow{4}{*}{ Categoria-C1 } & $\begin{array}{l}\text { E.10: "Esses terrenos vazios muitas vezes trazem risco para nós, porque eles ficam muito cer- } \\
\text { rado, cheio de mato, tudo vazio, então eu acredito que é um risco para gente. Pode ser também } \\
\text { que tem desses terrenos que as pessoas que fazem essas coisas erradas, que fumam droga, se } \\
\text { infiltram, então é até um risco para a gente." (grifo nosso) }\end{array}$ \\
\hline & $\begin{array}{l}\text { E. 17: "Eu acho que tem que ocupar, né? Porque as pessoas ficam muito vulneráveis a assalto, } \\
\text { estupro." (grifo nosso) }\end{array}$ \\
\hline & $\begin{array}{l}\text { E. 19: "Tem uns pedaços aqui que eu acho bem perigosos, terreno está vazio, cheio de mato, aí é } \\
\text { perigoso por causa de assalto, questão também de saúde pública, quanto mais terreno, mais lixo } \\
\text { vai se acumulando, água que fica empoçada trazendo doenças." (grifo nosso) }\end{array}$ \\
\hline & $\begin{array}{l}\text { E. 28: "Esses terrenos vazios que estão aí juntando lixo, sujeira e tudo mais são até perigosos } \\
\text { para a gente que vive aqui nessa redondeza, por exemplo 11:00 você não pode sair com o celular } \\
\text { aqui na rua senão é assaltado. [...]. E esses terrenos contribuem muito para isso. Se você andar } \\
\text { nesse bairro aqui, você vai ver que ali para baixo é 'Zona Vermelha', é o 'rip-rap'. E são muitos } \\
\text { terrenos abandonados, e isso ajuda muito o tráfico aqui." (grifo nosso) }\end{array}$ \\
\hline
\end{tabular}

Quadro 2 - Verbalizações dos entrevistados relativas ao uso dos terrenos para atividades comerciais e de serviços

\begin{tabular}{|c|c|}
\hline & Verbalizações \\
\hline \multirow{3}{*}{ Categoria - C3 } & $\begin{array}{l}\text { E. 3: "Podia ter uma feira, dividir um terreno em boxes, porque a nossa feira aqui do bairro é } \\
\text { totalmente desorganizada, em cima de calçada." Homem, } 42 \text { anos. (grifo nosso) }\end{array}$ \\
\hline & E. 18: "Podia ser usado para fazer uma atividade agrícola." Mulher, 52 anos. (grifo nosso) \\
\hline & $\begin{array}{l}\text { E. 30: "Acho que esses terrenos poderiam ser utilizados para hortas, para gerar um tipo de renda } \\
\text { ou uma criação de feira nessas áreas. Se analisarmos um pouco mais, vendo a realidade de cada } \\
\text { área em que esses terrenos se encontram, tem como pensar em algo mais que servisse para a } \\
\text { comunidade." Homem, } 32 \text { anos. (grifo nosso) }\end{array}$ \\
\hline
\end{tabular}

sobretudo o uso de residentes locais para sua realização e a destinação dos alimentos ao consumo próprio, à troca ou à comercialização local), demonstraram-se receptivos à ideia (87\%) e, paralelamente, apontaram possíveis benefícios dessa prática (Gráfico 7) e os tipos de acordo para a utilização desses terrenos para o cultivo de alimentos (Gráfico 8).
Embora a maioria dos entrevistados não tenha opinado (C5-37\%), a indicação de que a concessão desse uso deveria ser feita a partir de um acordo documentado (C1-30\%) prevaleceu sobre os demais tipos de acordo sugeridos. Esse dado traz a perspectiva da responsabilização, o que coaduna com boas práticas de governança. 
Gráfico 7 - Distribuição das opiniões quanto aos benefícios do cultivo de alimentos nos terrenos ociosos

\section{C3 - Abastecimento alimentar C1 - Financeiro C2 - Ocupação Não conclusivo \\ C4 - Não opinou ou não soube responder

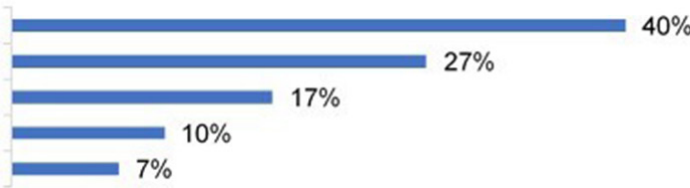

\section{Legenda}

C1 - Financeiros - Relativo ao conjunto de receitas e despesas.

C2 - Ocupação - Relativo ao ato de trabalhar em algo. Preenchimento de uma função que estava livre.

C3 - Abastecimento alimentar - Relativo a "comer regularmente alimentos de qualidade e adequados aos hábitos culturais, com base em práticas saudáveis" (Maluf, 2007 apud Pires e Brito, 2015).

Gráfico 8 - Distribuição das categorias tipos de acordo

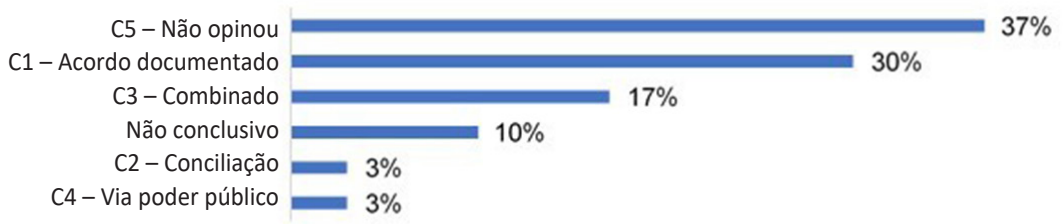

\section{Legenda}

C1 -Acordo documentado - Relativo a um ajuste formal, decisão ou resolução conjunta gravada em documento.

C2 - Conciliação - Consiste na intervenção de um mediador que auxiliará aqueles que estão em conflito para que negociem no sentido de elaborar um acordo que atenda aos interesses de todos os envolvidos.

C3 - Combinado - Relativo à ação de entendimento entre duas ou mais pessoas.

C4 - Via poder público - Quando a soma de interesses particulares, representada com a supremacia do Poder Público, busca a conciliação de um aparente conflito.

\section{Estratégias de implantação da agricultura urbana no Campos Sales}

No sentido de conceber estratégias de implantação de um projeto de agricultura urbana na localidade do estudo, posteriormente a realização da entrevista semiestruturada, pediu-se dos 30 entrevistados, num primeiro momento, que valorassem em ordem decrescente 11 aspectos - já documentados em estudos e experiências realizadas em diversos estados brasileiros, bem como em outros países - relativos ao desenho projetual para concretização da prática da agricultura urbana em terrenos ociosos como estratégia de governança territorial.

A pontuação atribuída pelos entrevistados a cada um dos aspectos gerou um diagrama de caixa (Figura 5), no qual as caixas retangulares representam a dispersão das respostas (valoração atribuída), ao passo que a linha horizontal interna a cada retângulo indica o valor de tendência central das respostas - mediana - separando a amostra em duas porções, $50 \%$ acima e abaixo do referido valor. 
Figura 5 - Diagrama de caixa (boxplot) da distribuição da pontuação atribuída a 14 aspectos relativos ao desenho projetual para a concretização da prática da agricultura urbana, em terrenos ociosos, como estratégia de governança territorial, resultante de 30 entrevistas

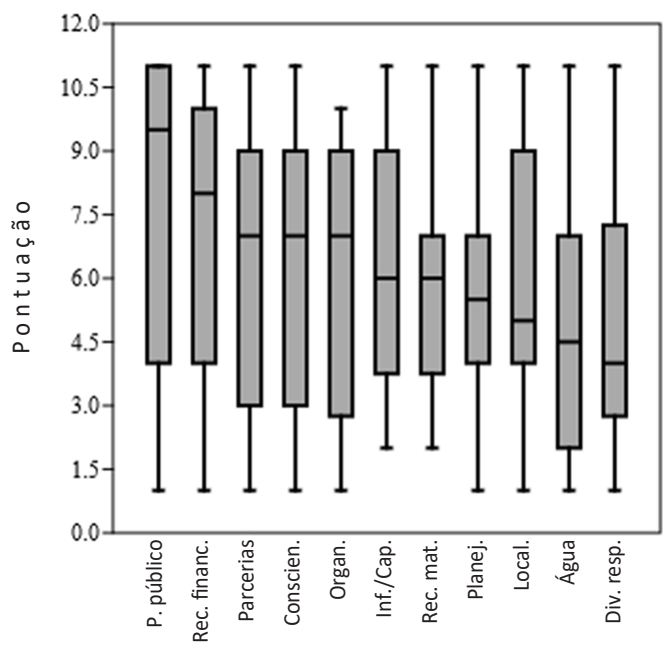

\author{
Legenda \\ P. público - Ter auxílio do poder público. \\ Rec. financ. - Ter recursos financeiros. \\ Parcerias - Ter parcerias com outras instituições (escolas, ONGs, \\ universidades). \\ Conscien. - Conscientização da comunidade sobre agricultura e \\ meio ambiente. \\ Organ. - Organização da comunidade/população interessada. \\ Inf./Cap. - Ser oferecida informação técnica/cursos de capacita- \\ ção para a comunidade. \\ Rec. mat. - Ter acesso aos recursos materiais como terra fértil, \\ adubos, sementes. \\ Planej. - Ter planejamento coletivo e trabalho diário da popula- \\ ção envolvida. \\ Local. - Ter acesso a locais para o desenvolvimento da agricultura \\ urbana. \\ Água - Ter acesso à água limpa para aguar as plantas cultivadas. \\ Div. resp. - Ter divisão de responsabilidades entre as pessoas da \\ comunidade interessadas na prática da agricultura urbana.
}

Fonte: elaborado pela autora utilizando o software Past 3.24.

Da análise do diagrama de caixa, "Ter auxílio do poder público" e "Ter recursos financeiros" são os aspectos primordiais na articulação de um projeto que estimule a prática da agricultura urbana. Isto porque $50 \%$ da população atribuiu aos mesmos os mais altos valores (entre 11 e 9,5 para "Ter auxílio do poder público" e entre 11 e 8 para "Ter recursos financeiros"). Os valores das medianas situados, respectivamente, em ' 9,5 ' e ' 8 ', ocupando as mais altas posições, comparativamente aos valores das medianas dos demais aspectos, reforçam esse dado.

Isto, enfocando a discussão acerca da participação cidadã e de uma cidadania ativa em prol da resolução de problemas socioambientais no nível comunitário, pesa contra o potencial da prática da agricultura urbana constituir-se em estratégia de governança territorial, no entanto, isto não diminui a importância desse tipo de articulação.

Nesse sentido, embora a literatura acadêmica brasileira se encontre permeada por experiências acerca da agricultura urbana - incluindo-se estudos em cidades com características fisiográficas e socioeconômica-ambientais próximas à realidade de Manaus, como a cidade de Belém -, elas incidem sobre a agricultura realizada em quintais urbanos ou agroflorestais em propriedades particulares, em áreas periurbanas vinculadas ao setor primário, a manutenção de hábitos culturais, no entanto, sem enfocar os vínculos desse tema com a governança territorial e o planejamento 
urbano, principalmente no que tange à utilização de terrenos ociosos entremeados na maIha urbana.

Dessa forma, do universo de experiências de estímulo à agricultura urbana fomentadas com o apoio financeiro/institucional de órgãos governamentais e/ou não governamentais, aproximando-se do que a análise do diagrama de caixa sugere para os dois primeiros itens, destacam-se os projetos: Centros de Vivência Agroecológicos (Belo Horizonte) e Hortas Cariocas (Rio de Janeiro).

A experiência dos Centros de Vivência Agroecológicos (Cevaes) é bastante exemplificadora dos benefícios que podem advir de processos locais participativos multiautorais na identificação, planejamento e implementação de políticas e ações estratégicas para desenvolvimento da agricultura urbana (Lovo, 2011).

Lovo (ibid.) explica que o sucesso dos Cevaes pode ser traçado cronologicamente remontando ao início da década de 1990 - devido a uma série de fatores, dentre eles: a implantação da primeira gestão democrática popular no município de Belo Horizonte - incluindo-se o programa do orçamento participativo, a efetivação da política municipal de segurança alimentar, com a criação da Secretaria Municipal Adjunta de Abastecimento (Smaab) e a implantação da Agenda 21 local.

Nesse sentido, firmou-se uma parceria entre a Secretaria Municipal Adjunta de Abastecimento e a Secretaria Municipal de Meio Ambiente (SMMA), possibilitando a aprovação de recursos para a implantação de três Cevaes, durante o processo do Orçamento Participativo Setorial do Meio Ambiente do ano de 1994. Recursos para instalação de um quarto Cevae foram viabilizados pelo Fundo Life/ Pnud/ONU, mediante repasse à SMMA, desde que atendendo à exigência de que houvesse a cooperação entre o poder público, as organizações da sociedade civil e representantes de comunidades. Assim a ONG Rede de Intercâmbio de Tecnologias Alternativas (Rede-MG) juntou-se ao projeto, responsabilizando-se pela operacionalização dos Centros, coordenação executiva, acompanhamento técnico e adequação das metodologias adotadas (ibid.).

Ainda no que tange à aproximação da experiência dos Cevaes com a concepção de criação de um projeto de agricultura urbana no Campos Sales, perpassando além do apoio financeiro do poder público (direto ou via outras instituições/organizações), a questão da governança territorial e do planejamento urbano, destaca-se que a intenção dos Cevaes em propiciar a implementação de experiências-piloto demonstrativas da viabilidade de meIhoria das condições socioambientais da qualidade de vida - com a participação popular partiu de um diagnóstico sobre as condições de ocupação do espaço urbano nas periferias de Belo Horizonte (ibid.). Esse dado, comparativamente ao cenário da administração urbana da cidade de Manaus, traz à tona a necessidade urgente de realização de um cadastro de áreas potencialmente úteis para a prática da agricultura urbana, conforme já discutido.

No ano 2000, os Cevaes foram regulamentados como equipamentos públicos comunitários de Política de Meio Ambiente e Segurança Alimentar, com atuação em programas de intervenção socioambiental (ibid.), e, atualmente, findada a parceria entre a ONG Rede-MG e a Prefeitura de Belo Horizonte, eles estão sob gestão da Fundação de Parques Municipais (FPM), criada em 2005, vinculada à Secretaria Municipal de Políticas Urbanas (Coutinho, 2010). 
A contribuição que o Projeto Hortas Cariocas, iniciado em 2006 pela Secretaria Municipal de Meio Ambiente - SMAC do Rio de Janeiro traz, à perspectiva de criação de um projeto de agricultura urbana no Campos Sales com apoio do poder público, abarca diretamente a questão do aproveitamento de terrenos ociosos disponíveis na malha urbana.

Assim sendo, os objetivos do projeto incluem: contribuir com o desenvolvimento socioeconômico local a partir da capacitação da população carente; reduzir os índices de ocupação irregular de terrenos ociosos; elevar os níveis de inclusão social e oferecer o direito humano básico a uma alimentação saudável e de qualidade (O'Reilly, 2014).

No que concerne à operacionalização do projeto, há o estímulo a uma participação social ativa. Nesse sentido, o primeiro passo para a instalação de uma unidade produtiva em terrenos de áreas públicas da cidade consiste no encaminhamento de uma solicitação por escrito à prefeitura do Rio de Janeiro, ou seja, o interesse tem que ser manifestado no sentido comunidade - prefeitura e não o contrário. O’Reilly (ibid.) pontua que dessa forma possibilitam-se a mobilização e o envolvimento dos comunitários já no início do processo de implantação.

Essa participação manifesta-se também posteriormente, quando da organização das equipes de comunitários que irão gerir a horta. Nesse sentido, os membros da comunidade são indicados pela associação de moradores, dando preferência às pessoas que já possuam experiência prévia com a atividade e/ou que já tenham sido capacitadas por algum outro programa da prefeitura. Esses indicados são, então, entrevistados pelos gestores do projeto, a fim de que seja escolhido um encarregado, o qual esteja apto a lidar com diversos aspectos inerentes à manutenção da horta - englobando-se questões técnicas, com a equipe e, mesmo, problemas relacionados ao cenário de vulnerabilidade socioambiental em que as comunidades se encontram (lançamento de lixo nas hortas, invasão de animais, enchentes) (ibid.).

Atualmente, o programa Hortas Cariocas conta com 40 unidades produtivas (17 unidades em comunidades de baixa renda e 23 em equipamentos da Secretaria Municipal de Educação - SME), produzindo uma média de 70 toneladas/ano de alimentos orgânicos (frutas, verduras e legumes), e é um dos candidatos a integrar a lista oficial da Organização das Nações Unidas - ONU de projetos aceleradores dos Objetivos de Desenvolvimento Sustentável (Semac, 2020; Prefeitura do Rio de Janeiro, 2020).

Voltando-se à discussão sobre planejamento urbano, a indicação de que um projeto de agricultura urbana deve ser precedido pelo auxílio do poder público bem como pela oferta de recursos financeiros aproxima-se da abordagem de planejamento e gestão urbana do tipo top-down (de cima para baixo). Esta se fundamenta na centralidade dos atores e das instituições públicas concernentes a formulação e implementação de políticas públicas (Monteiro, 2017), tendo esta entrado em colapso a partir da década de 1970.

Retomando a análise do diagrama de caixa, tem-se a equiparação entre os valores atribuídos aos itens "Ter parceria com outras instituições", "Conscientização da comunidade sobre agricultura urbana e meio ambiente" e "Organização da comunidade/população 
interessada", tanto no que diz respeito à dispersão dos valores atribuídos a esses itens, quanto aos valores das medianas, que, em conjunto, ocupam a terceira posição de maior valoração.

Esse dado traz a perspectiva de que, para uma parte dos entrevistados, a exequibilidade de um projeto de agricultura urbana depende de aspectos que concernem à participação cidadã em nível comunitário. Iniciativas dessa natureza possuem forte vínculo com a abordagem bottom-up (de baixo para cima) de planejamento urbano, no sentido de que é a partir de ações populares comunitárias que se dá a ativação de áreas urbanas subutilizadas ou ociosas, contribuindo para o desenho de soluções e respectivo desenvolvimento da localidade onde essas ações se inserem (Gomes, Gomes e Melo, 2010).

A respeito dessa abordagem, Fontes et al. (2018) destacam que é em face da morosidade ou ineficiência do poder público em executar estratégias de longo prazo, que surgem, cada vez mais frequentemente, iniciativas comunitárias para transformação de espaços cotidianos, a exemplo da prática da agricultura urbana realizada desde 2014 na Horta General Glicério, no Rio de Janeiro, que é uma obra comunitária com permissão informal de ocupação de terreno privado.

Embora as opiniões da população entrevistada indiquem duas concepções distintas de articulação de um projeto de agricultura urbana, com uma delas guardando grande paralelismo com uma abordagem de planejamento e gestão urbana do tipo top-down e a outra tangenciando uma estratégia de planejamento e gestão urbana do tipo bottom-up, ressalta-se, no entanto, que essa distinção não implica que essas concepções sejam mutuamente excludentes.
Nesse sentido, Sennet (2015) aponta que no que concerne à escolha entre abordagens top-down e bottom-up não há uma solução. A contradição que elas representam é essencial à vida das cidades, devendo haver ambas. 0 autor defende que é possível que comunidades locais criem soluções de baixo para cima, inclusive para os problemas estruturais das cidades.

0 dado de que as medianas dos valores relativos aos aspectos "Ter planejamento coletivo e trabalho diário da população envolvida" e "Ser oferecida informação técnica/ cursos de capacitação para a comunidade" são inferiores às medianas dos já citados aspectos "Organização da comunidade/população interessada" e "Ter parceria com outras instituições" conota uma certa inconsistência nas respostas, já que se trata de aspectos inter-relacionados e interdependentes.

Superando essa possível inconsistência, é possível inferir de um modo geral que, para a viabilização da prática da agricultura urbana, o conjunto de critérios relativos a recursos humanos ("Organização da comunidade/população interessada", "Conscientização da comunidade sobre agricultura urbana e meio ambiente" e "Ter parceria com outras instituições") possui uma valoração maior do que o conjunto de critérios relativos ao acesso a recursos físicos propriamente, nos quais se englobam "Ter acesso aos recursos materiais como terra fértil, adubos, sementes", "Ter acesso a locais para o desenvolvimento da agricultura urbana" e "Ter acesso a água limpa para aguar as plantas".

Passando a uma observação mais atenta da valoração dos itens relativos aos recursos materiais, destacam-se alguns pontos fortes e fragilidades. No que tange a "Ter acesso aos recursos materiais como terra fértil, adubos, 
sementes", a menor dispersão de valores, bem como um valor de tendência central mais baixo, comparativamente aos itens previamente analisados, justifica-se diante da ênfase dos comunitários relativa ao domínio de práticas de enriquecimento do solo com restos de vegetais in-natura e de compostagem e ao hábito da troca entre vizinhos da comunidade, tanto de sementes, quanto de mudas. Nesse sentido, um ponto forte na articulação necessária entre os comunitários para a concretização de inciativas de agricultura urbana.

Além disso, as fragilidades tangenciam os itens "Ter acesso a água limpa para aguar as plantas" e "Ter acesso a locais para o desenvolvimento da agricultura urbana". Relativo ao primeiro, o valor posicional da mediana do referido item indica uma baixa valoração atribuída a ele, um dado questionável, não condizendo com os apontamentos de que a comunidade carece de estruturas de abastecimento de água e de saneamento básico e que, portanto, este seria um aspecto de grande relevância para a concretização da AU em terrenos na localidade.

Com relação a "Ter acesso a locais para o desenvolvimento da agricultura urbana", embora haja uma dispersão simétrica dos valores atribuídos, o valor de tendência central é o segundo menor quando comparado ao dos demais itens analisados. Isto pode sugerir, paralelamente ao dado de que o hábito de cultivar está amplamente difundido entre os entrevistados, que atividades relativas à agricultura urbana são mais visibilizadas sendo concebidas no próprio limite domiciliar e não como uma prática comunitária, apesar da potencial oferta de terrenos para tal atividade, cuja possível utilização consistiria em uma estratégia de governança territorial.

Por fim, a posição da mediana relativa ao aspecto "Ter divisão de responsabilidades entre as pessoas da comunidade interessadas na prática da agricultura urbana" é outro dado não contundente diante do seu afastamento relativo aos aspectos com os quais deveria estar inter-relacionado, quais sejam "Organização da comunidade/população interessada" e "Ter planejamento coletivo e trabalho diário da população envolvida".

Complementarmente à valoração desses aspectos e, ainda, no sentido de auxiliar o desenho de um projeto de agricultura urbana, solicitou-se que os entrevistados classificassem um conjunto de benefícios advindos com a prática da agricultura urbana (igualmente já documentados em estudos e experiências realizadas em diversos estados brasileiros, bem como em outros países) em classes rotuladas como: "Fatores pouco importantes", "Fatores importantes" e "Fatores muito importantes", com o intuito de mapear quais deles seriam mais atrativos ao envolvimento dos comunitários na implementação hipotética do projeto supracitado.

Da classificação dos benefícios da agricultura urbana nos rótulos indicados, gerou-se uma planilha de dados binários (0-ausência e 1-presença), a qual serviu de base para a geração do dendograma de pareamento dos entrevistados, empregando-se o Índice de Similaridade de Morisita (Figura 6). 
Figura 6 - Dendograma do pareamento dos entrevistados em função da classificação dos benefícios acerca da agricultura urbana

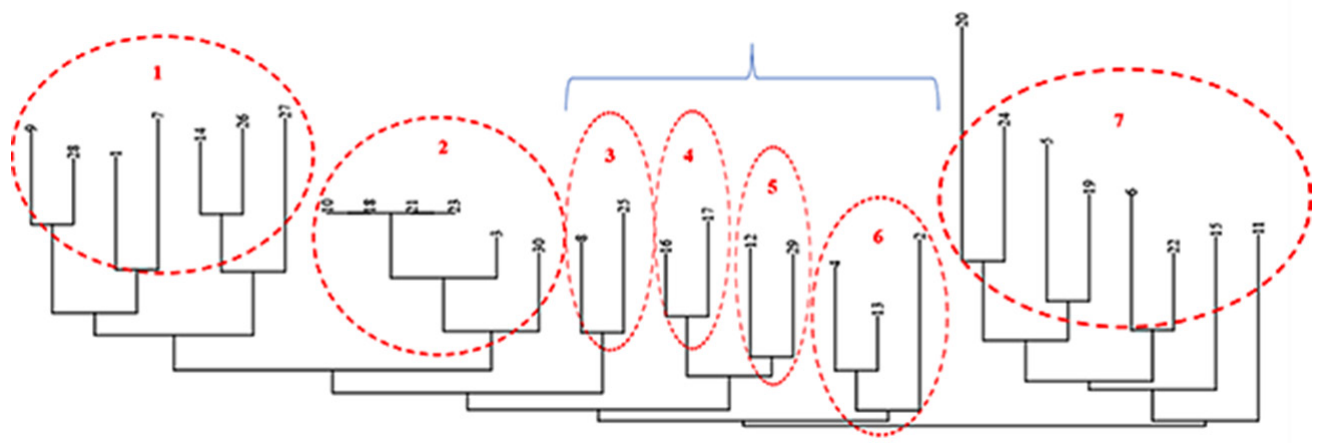

Benefícios da Agricultura Urbana sujeitos a classificação conforme juízo de valores dos entrevistados.

\begin{tabular}{|l|l|}
\hline $\begin{array}{l}\text { Pode ser uma forma de lazer, de relaxamento e alívio de estresse, } \\
\text { melhorando a saúde psicológica dos moradores da comunidade. }\end{array}$ & $\begin{array}{l}\text { Pode ser uma forma de ocupação para residentes desempregados, } \\
\text { moradores de rua e jovens e adultos em situação de risco social. }\end{array}$ \\
\hline Pode ser uma forma de promover a atividade física. & $\begin{array}{l}\text { Pode ser uma forma de diminuir a quantidade de invasões } \\
\text { domiciliares, furtoseaatividadedotráficodedrogasnacomunidade. }\end{array}$ \\
\hline $\begin{array}{l}\text { Pode ser uma forma de aumentar o acesso a alimentos saudáveis } \\
\text { e nutritivos. }\end{array}$ & Pode ser uma forma de promover o senso de comunidade. \\
\hline $\begin{array}{l}\text { Pode ser uma forma de permitir o controle da própria } \\
\text { alimentação. }\end{array}$ & $\begin{array}{l}\text { Pode ser um espaço para o compartilhamento de informações/ } \\
\text { experiências. }\end{array}$ \\
\hline Pode ser uma forma de fortalecer a economia local. & $\begin{array}{l}\text { Pode ser uma forma de permitir o aproveitamento dos restos de } \\
\text { alimentos naturais. }\end{array}$ \\
\hline Pode ser uma forma de trabalho rentável. & $\begin{array}{l}\text { Pode ser uma forma de reduzir o impacto do ser humano no meio } \\
\text { ambiente. }\end{array}$ \\
\hline Pode ser uma forma de permitir a economia de renda. & Pode ser um espaço para a prática da educação ambiental. \\
\hline
\end{tabular}

Fonte: elaborado pela autora utilizando o software Past 3.24.

Da análise visual do dendrograma, é possível diagnosticar três clusters que se destacam. 0 cluster 1 possui como características homogeneizadoras as classificações dos possíveis benefícios da $\mathrm{AU}$ relativos ao fortalecimento da economia local e à economia de renda, classificados como muito importantes e, em contrapartida, os benefícios de ser uma fonte de lazer e relaxamento, bem como de promover a atividade física, considerados pouco importantes.
Por sua vez o cluster 2 agrupa os indivíduos conforme a prevalência de benefícios classificados como "muito importantes". Nesse sentido, para os indivíduos 10, 18, 21 e 23, todos os benefícios são igualmente muito importantes.

O cluster 7 opõe-se ao cluster 1 exatamente no que concerne aos aspectos da AU relativos à promoção de atividade física e de ser uma fonte de lazer e relaxamento. Nesse sentido, para esse grupo de indivíduos, esses benefícios são considerados muito importantes. 
Os clusters 3, 4, 5 e 6 representam uma transição da predominância de benefícios classificados como "muito importantes" nos clusters 1 e 2 para a predominância de benefícios "importantes" no cluster 7.

É ainda de grande relevância o dado de que os benefícios relativos ao meio ambiente não se constituíram como principal característica aglutinadora para nenhum dos clusters.

Diante do exposto, é possível perceber que os benefícios de natureza financeira e social se equiparam enquanto aspectos motivacionais subjacentes ao envolvimento dos comunitários em um possível projeto de agricultura urbana. Destaca-se, no entanto, que os benefícios de natureza ambiental não possuem relevância majoritária em nenhum dos agrupamentos de entrevistados diagnosticados.

\section{Conclusões}

A discussão em torno da agricultura urbana como uma estratégia de governança territorial na localidade Campos Sales é desafiado$\mathrm{ra}$, pois envolve aspectos inter-relacionados às dinâmicas recorrentes ao contexto local. Exemplo disso são a precária infraestrutura social e a presença de poderes paralelos como o da criminalidade.

A despeito do que se poderia potencializar com projetos relativos à agricultura urbana no município de Manaus, foram inviabilizados o número de dois, devido à interpretação dada ao artigo 59 da Lei Orgânica do Município. Esta impõe restrições e compromete iniciativas de gestão que promovam novas formas de gestão organizacional do espaço urbano, provenientes de ações parlamentares voltadas à elaboração de leis com impacto social, político e econômico.

Ainda nesse sentido, a efetivação de estratégias de governança territorial e urbana no Município carece de discussões mais profundas que englobem, inclusive, aspectos relativos à sua estruturação e organização administrativa, em particular no tocante a ações deliberativas descentralizadas e intersetoriais, que envolvam órgãos estratégicos no trato da questão dos terrenos ociosos, particularmente o Instituto Municipal de Planejamento Urbano e Secretaria Municipal de Finanças, Tecnologia da Informação e Controle Interno - Semef, membros natos do Conselho Municipal de Gestão Estratégica e a Secretaria Municipal de Meio Ambiente e Sustentabilidade - Semmas.

Na perspectiva de que a agricultura urbana é um tema aglutinador, sua contribuição concreta passa pelo envolvimento que ela propicia na integração de fluxos em redes sociais e na geração de interesse dos cidadãos, nos diversos setores e instâncias da vida em sociedade. É possível vislumbrar duas concepções distintas de articulação de um projeto sobre o tema. Uma alicerçada no auxílio do poder público e na provisão de recursos financeiros, guardando grande paralelismo com uma abordagem de planejamento e gestão urbana do tipo top-down; e a outra, alicerçada nos aspectos relativos a uma atuação cidadã, tangenciando uma estratégia de planejamento e gestão urbana do tipo bottom-up.

Se, por um lado, as entrevistas conotam intenções individuais voltadas ao atendimento do interesse coletivo, por outro, a inexistência de uma organização social comunitária, na forma de uma associação de moradores, constitui 
uma fragilidade da atuação cidadã, dificultando a ascensão de uma governança territorial profícua, inclusive pelos meios institucionalizados de participação social.

No que tange aos benefícios que motivariam o envolvimento da população em atividades desse mote, as entrevistas demonstraram que há uma equiparação entre os aspectos de natureza financeira e social. Além disso, os aspectos de natureza ambiental não possuem relevância, nesse envolvimento, para os atores sociais.

Assim, diante de uma atuação cidadã incipiente, num contexto de precária infraestrutura cívica, a agricultura urbana não é visibilizada como uma estratégia de governança territorial capaz de minimizar as problemáticas socioambientais ali recorrentes e de superação de dificuldades socioeconômicas.

\section{[1] https://orcid.org/0000-0001-6859-0113.}

Universidade Federal do Amazonas, Centro de Ciências do Ambiente, Programa de Pós-Graduação em Ciências do Ambiente e Sustentabilidade na Amazônia. Manaus, AM/Brasil.

camilamargem83@gmail.com

\section{[II] https://orcid.org/0000-0002-6812-729X}

Universidade Federal do Amazonas, Faculdade de Ciências Agrárias, Departamento de Ciências Fundamentais e Desenvolvimento Agrícola. Manaus, AM/Brasil.

nmerinato@gmail.com

\section{Referências}

ALTIERI, M. (2010). Agroecologia, agricultura camponesa e soberania alimentar. Revista NERA. Presidente Prudente, ano 13, n. 16, pp. 22-32.

AUBRY, C.; POURIAS, J. (2013). L'agriculture urbaine fait déjà partie du "métabolisme urbain": Économie et stratégies agricoles. Déméter, Club Déméter, pp. 135-155. Disponível em: https:// hal.archives-ouvertes.fr/hal-01198075/document. Acesso em: 18 abr 2018.

BICALHO, A. M. S. M. (2005). Transformações do sistema de produção agrícola na região de Manaus. In: X ENCONTRO DE GEÓgRAFOS DA AMÉRICA LATINA. Anais... São Paulo, pp. 2012-2035.

CÂMARA, J. B. D. (2013). Governança ambiental no Brasil: ecos do passado. Revista de Sociologia e Política. Curitiba, v. 21, n. 46, pp. 125-146.

CÔRTE, D. A. A. (1997). Planejamento e gestão de APAs: enfoque institucional. Brasília, Edições Ibama/ MMA.

COUTINHO, M. N. (2010). Agricultura urbana: práticas populares e sua inserção em políticas públicas. Dissertação de mestrado. Belo Horizonte, Universidade Federal de Minas Gerais.

COUTINHO, M. N.; COSTA, H. S. M. (2011). Agricultura Urbana: prática espontânea, política pública e transformação de saberes rurais na cidade. Geografias. Belo Horizonte, v. 7, n. 2, pp. 81-97. 
DALLABRIDA, V. R. (2011). “Concepções teóricas que sustentam o debate sobre descentralização política-administrativa". In: DALLABRIDA, V. R. (org.) Governança territorial e desenvolvimento: descentralização política-administrativa, estruturas subnacionais de gestão do desenvolvimento e capacidades estatais. Rio de Janeiro, Garamond.

DAMBRÓS, C.; MIORIN, V. M. F. (2011). Contribuições à reflexão do rural no urbano: agricultura urbana. Geonordeste, ano XXII, n. 2, pp. 65-78.

DUMAZEDIER, J. (2000). Lazer e cultura popular. São Paulo, Perspectiva.

ESPADA, A. L. V.; SOBRINHO, M. V. (2015). Manejo comunitário e governança ambiental para o desenvolvimento local: análise de uma experiência de uso sustentável de floresta na Amazônia. Administração Pública e Gestão Social, v. 7, n. 4, pp. 169-177.

FALEIROS, M. I. L. (1980). Repensando o lazer. Perspectivas. São Paulo, v. 3, pp. 51-65.

FÁTIMA DA SILVA, L. (2018). O Tema 917 de Repercussão Geral do STF como novo paradigma na análise da iniciativa reservada no processo legislativo. Revista Procuradoria da Câmara Municipal de São Paulo. São Paulo, v. 6, n. 1, pp. 27-61.

FIgUeIREDO, H. P.; CONSTANTINO, M.; BARROS, J. H. S.; COSTA, R. B. (2017). Políticas públicas e fragilidades na gestão de Unidades de Conservação urbanas no Brasil. Multitemas. Campo Grande, v. 22, n. 51, pp. 217-234.

FONTES, A. S.; GALARCE, F. E.; VALLE, L. M.; MOTTA, V. F.; FARIA, T. S. (2018). Táticas cidadãs para ativação de áreas subutilizadas: o caso das hortas comunitárias do Rio de Janeiro. Arq. Urb, n. 23, pp. 147-169.

FREY, K. (2007). Governança urbana e participação pública. RAC-Eletrônica, v. 1, n. 1, pp. 136-150. Disponível em: http://www.anpad.org.br/rac-e. Acesso em: 2 ago 2018.

GOMES, J. D.; GOMES, L. D.; MELLO, M. M. C. (2019). Urbanismo tático e o direito a cidade. Revista Políticas Públicas e Cidades. Belo Horizonte, v. 8, n. 4, pp. 40-51.

HOMMA, A. K. O. (2015). Os Desafios para uma nova agricultura na Amazônia. In: WORKSHOP DE PESQUISA E AGRICULTURA FAMILIAR: FORTALECENDO A INTERAÇÃO DA PESQUISA PARA INOVAÇÃO E SUSTENTABILIDADE NA AMAZÔNIA. Anais... Manaus, pp. 51-66.

IBAM - Instituto Brasileiro de Administração Municipal (2009). Manual do Prefeito. Disponível em: http://www.ibam.org.br/media/arquivos/estudos/manual_prefeito.pdf. Acesso em: 13 nov 2019.

JUNQUEIRA, L. A. P. (1998). Descentralização e intersetorialidade: a construção de um modelo de gestão municipal. Revista de Administração Pública. Rio de Janeiro, v. 32, n. 2, pp. 11-22.

KORNIN, T., MOURA, R. (2004). Metropolização e governança urbana: relações transescalares em oposição a práticas municipalistas. Revista GEOUSP - Espaço e tempo. São Paulo, n. 16, pp. 17-30.

LARA, P. F. N. S.; SANTOS, M. M. C.; COSTA, I. C. N. P.; VIEIRA, T. A. (2019). Estudos sobre agricultura urbana no Brasil no período de 2008 a 2017. Amazonia Investiga, v. 8, n. 20, pp. 124-134.

LARCHER, M. (2017). Câmara aprova Política Nacional de Agricultura Urbana. Disponível em: https:// www.camara.leg.br/noticias/527345-camara-aprova-politica-nacional-de-agricultura-urbana/. Acesso em: 16 mar 2020.

LEMOS, N. S.; ANDRADE, L. M. S.; MEDEIROS, V. A. S. (2015). Desafios do planejamento urbano no Brasil e seus marcos legais sob a ótica da agricultura urbana. Paranoá: Cadernos de Agricultura e Urbanismo, n. 14, pp. 61-70. 
LEUZINGER, M. D.; SCARDUA, F. P. (2011). "Unidades de conservação e planos diretores municipais". In: MILARÉ, E.; MACHADO, P. A. L. (orgs.). Doutrinas essenciais Direito Ambiental, v. III - Meio Ambiente Urbano. São Paulo, Thomson Reuters.

LIMA, A. J. R.; ABRUCIO, F. L.; SILVA, F. C. B. (2014). Governança dos recursos hídricos: proposta de indicador para acompanhar sua implementação. Disponível em: https://www.wwf. rg.br/?42942/Governana-dos-Recursos-Hdricos--Proposta-de-indicadores-para-acompanharsua-implementao. Acesso em: 23 jul 2018.

LOVO, I. C. (2011). Agricultura urbana: um elo entre o ambiente e a cidadania. Tese de doutorado. Florianópolis, Universidade Federal de Santa Catarina.

MARCHESAN, A. M. M. (2011). “Preservação ambiental e ocupação do espaço urbano à luz do Estatuto da Cidade (lei n.10.257/2001)". In: MILARÉ, E.; MACHADO, P. A. L. (orgs.) Doutrinas essenciais Direito Ambiental, v. III - Meio Ambiente Urbano. São Paulo, Thomson Reuters.

MARCONI, M. A.; LAKATOS, E. M. (2003). Fundamentos de Metodologia Científica. São Paulo, Atlas.

MASS, L.; MALVESTITI, R.; GONTIJO, L. A. (2020). O reflexo da ausência de políticas de incentivo à agricultura urbana orgânica: um estudo de caso em duas cidades no Brasil. Cadernos de Saúde Pública, v. 36, n. 8, pp. 1-12.

MAURANO, A. (2007). O poder legislativo municipal. Dissertação de mestrado. São Paulo, Universidade Presbiteriana Mackenzie.

MEDEIROS, R. (2006). Evolução das tipologias e categorias de áreas protegidas no Brasil. Ambiente \& Sociedade, v. 9, n. 1, pp. 41-64.

MONTEIRO, L. M. (2017). Modelo “top-down": uma reflexão sobre a implementação de políticas públicas e a participação dos gestores governamentais. Revista Gestão Organizacional. Chapecó, v. 9 , n. 3, pp. 25-35.

MORGAN, K.; SONNINO, R. (2010). The urban foodscape: world cities and the new food equation. Cambridge Journal of Regions, Economy and Society, v. 3, n. 2, pp. 209-224.

NASCIMENTO, Y. A. N. M. (2019). Do modelo interpretativo da iniciativa privativa do Poder Executivo. Disponível em: https://www.boletimjuridico.com.br/artigos/direito-constitucional/4361/domodelo-interpretativo-iniciativa-privativa-poder-executivo. Acesso em: 3 dez 2019.

O’REILLY, E. M. (2014). Agricultura Urbana - um estudo de caso do projeto Hortas Cariocas em Manguinhos, Rio de Janeiro. Monografia de graduação. Rio de Janeiro. Universidade Federal do Rio de Janeiro.

ORSINI, F.; KAHANE, R.; NONO-WOMDIM, R.; GIANQUINTO, G. (2013). Urban agriculture in the developing world: a review. Agronomy for Sustainable Development, n. 33, pp. 695-720.

PECI, A.; PIERANTE, O. P.; RODRIGUES, S. (2008). Governança e New Public Management: convergências e contradições no contexto brasileiro. Organizações \& Sociedade. Salvador, v. 15, n. 46, pp. 39-55.

PÊSSOA, C. C. (2005). Agricultura urbana e pobreza: um estudo no Município de Santa Maria - RS. Dissertação de mestrado. Santa Maria, Universidade Federal de Santa Maria.

PIRES, E. F. (2013). Direito constitucional legislativo. Rio de Janeiro, Lumen Juris.

PIRES, E. L. S.; FUINI, L. L.; MANCINI, R. F.; PICCOLI NETO, D. (2011). Governança territorial-conceito, fato e modalidades. São Paulo, Unesp. 
PIRES, S. S., BRITO, A. S. (2015). A discussão sobre produção e abastecimento enquanto estratégia de segurança alimentar. In: XV ENCONTRO DE GEÓGRAFOS DA AMÉRICA LATINA - EGAL. Anais... Havana. Disponível em: http://observatoriogeograficoamericalatina.org.mx/egal15/ Geografiasocioeconomica/Geografiarural/21.pdf. Acesso em: 12 jun 2018.

PREFEITURA DO RIO DE JANEIRO (2020). ONU inclui programa Hortas Cariocas, da Prefeitura do Rio, na lista de ações essenciais para alcançar os Objetivos do Desenvolvimento Sustentável. Disponível em: https://prefeitura.rio/meio-ambiente/onu-inclui-programa-hortas-cariocas-daprefeitura-do-rio-na-lista-de-acoes-essenciais-para-alcancar-os-objetivos-do-desenvolvimentosustentavel/. Acesso em: 2 jan 2021.

ROLNIK, R. (2001). Estatuto da Cidade - Instrumento para as cidades que sonham crescer com justiça e beleza. Cadernos Pólis, n. 4, pp. 5-9.

SEMMAS - Secretaria Municipal de Meio Ambiente e Sustentabilidade/Manaus (2018). Áreas protegidas. Disponível em: http://semmas.manaus.am.gov.br/areas-protegidas/. Acesso em: 19 jul 2018.

SENADO FEDERAL (2018). Projeto de lei do Senado n. 353, de 2017. Disponível em: https://www25. senado.leg.br/web/atividade/materias/-/materia/130955. Acesso em: 16 mar 2020.

SENNET, R. (2015). Como criar cidades juntos? Disponível em: https://piseagrama.org/como-criarcidades-juntos/. Acesso em: 27 nov 2019.

SMAC - Secretaria Municipal de Meio Ambiente/Rio de Janeiro (2020). Hortas cariocas. Disponível em: https://www.rio.rj.gov.br/web/smac/hortas-cariocas. Acesso em: 17 nov 2019.

STF - Superior Tribunal Federal (2016a). Repercussão Geral reconhecida com mérito julgado. ARE 878.911 RG, rel. min. Gilmar Mendes, j. 29-9-2016, P, DJE de 11-10-2016, Tema 917. Disponível em: http://www.stf.jus.br/portal/constituicao/artigobd.asp?item=\%20797. Acesso em: 9 dez 2019.

(2016b). Repercussão Geral no Recurso Extraordinário com agravo 878.911 Rio de Janeiro. Disponível em: http://redir.stf.jus.br/paginadorpub/paginador.jsp?docTP=TP\&docID=11828222. Acesso em: 9 dez 2019.

(2019). Tema 917. Disponível em: http://www.stf.jus.br/portal/constituicao/artigobd. asp?item=\%20797. Acesso em: 9 dez 2019.

THULER, A. (2017). STF reafirma sua jurisprudência e vereador pode propor leis que criem despesas para o município. Disponível em: https://athuler.jusbrasil.com.br/artigos/518446173/ stf-reafirma-sua-jurisprudencia-e-vereador-pode-propor-leis-que-criem-despesas-para-omunicipio?ref=serp. Acesso em: 3 dez 2019.

VIDEIRO ROSA, P. P. (2011). Políticas públicas em agricultura urbana e periurbana no Brasil. Revista Geográfica da América Central, v. 2, n. 47E, pp. 1-17. 
